\title{
O imaginário da maternidade em Frida Kahlo
}

\author{
Ciro Inácio Marcondes \\ Doutor; UniProjeção, Brasília, DF, Brasil \\ ciroimarcondes@hotmail.com
}

\section{Vanessa Daniele de Moraes}

Doutoranda; Universidade de Brasília, Brasília, DF, Brasil

quantasvanessas@gmail.com

\section{Resumo}

O imaginário da dor e da maternidade em Frida Kahlo suscita uma reflexão sobre uma harmonia entre as imagens presentes na consciência, em contraposição com o campo onírico. Neste sentido, como pensar o surrealismo com que muitos críticos insistem em rotular a arte de Frida? Nosso método se baseia na análise de algumas pinturas de Frida e de seu diálogo com o pensamento fenomenológico acerca das imagens, questionando - movimento surrealista como mera manifestação do inconsciente na arte. A noção de maternidade está em concordância com o pensamento dos agrupamentos sociais e de esferas, postulado pelo filósofo Peter Sloterdijk. Nosso objetivo é averiguar de que maneira os objetos artísticos de Frida Kahlo revelam uma existência da dor e do maternal enquanto dado imediato da consciência.

\section{Palavras-chave}

Imaginário da maternidade. Frida Kahlo. Aborto. Dor. Consciência.

Mi sangre es un milagro que, desde mis venas cruza el aire de mi corazón al tuyo.

Frida Kahlo

A arte de Frida Kahlo (1907-1954) é provocadora e aborda assuntos tabu, como o sangue, a doença, a morte ou fetos abortados, por exemplo. Polêmica foi também sua vida pessoal e muitos desses trágicos acontecimentos estão representados nas telas da artista, que expande um imaginário da dor e da maternidade. A arte de Frida comunica; fala por 
imagens e nos seduz. De que maneira, entretanto, o imaginário maternal emerge em sua obra?

As imagens aparentemente deslocadas, em Frida, possuem coerência. Os elementos estão sempre conectados com sua vida e com um sofrimento que a acompanhou da infância até a morte. Frida teve muita dor física devido às fragilidades de seu corpo - teve poliomielite quando criança, o que a deixou com uma perna mais curta e atrofiada. Por esse motivo ela passa a usar saias longas e calças compridas constantemente para esconder a deficiência. Aos 18 anos, um grave acidente entre um bonde e o ônibus em que estava com seu namorado Alejandro Gómez Arias deixou-a acamada por muito tempo e com sequelas físicas pelo resto da vida, especialmente na coluna.

A relação conturbada com o artista Diego Rivera, com quem se casou, se separou e reatou por diversas vezes, foi um fator agravante no estado emocional de Frida. Diego foi o seu grande amor e um de seus maiores desgostos foi quando ele passou a ter uma relação extraconjugal com sua irmã mais nova, Cristina, por quem ela tinha grande apreço. Além dessas mazelas, após o acidente que deixaria muitas marcas em seu corpo, veio também a impossibilidade de gestar, o que foi traumático para uma mulher que desejava muito ser mãe. É nessa ferida que queremos tocar: a maternidade (ou melhor, a ausência dela) em Frida. Neste artigo, pretendemos tomar a ideia do imaginário da maternidade em Frida e analisar seis pinturas da artista, além da contribuição de seu diário, que não deixa de nos remeter a imagens biográficas ligadas à dor e à maternidade. Tais pinturas são: Mi nana y yo, de 1937; El abrazo de amor entre el universo, la tierra (México), yo, Diego y el señor Xólotl, de 1949; Henry Ford o la cama volando, de 1932; Mi nacimiento, 1932; El sueño o La cama, 1938; Frida y el aborto, 1932 (FRIDA..., 2005; FRIDA..., 2015). A noção de imaginário que utilizaremos se fundamenta no pensamento fenomenológico de Jean Paul Sartre (consciência das imagens) e dialoga também com Gaston Bachelard (imagens poéticas) e Gilbert Durand (simbologias). 0 arcabouço filosófico acerca da maternidade foi construído a partir de leituras de Peter Sloterdijk, também herdeiro da fenomenologia.

Apesar de Frida Kahlo ser classificada como surrealista, a artista mexicana nunca considerou sua obra fantasiosa ou surreal. Uma frase que se tornou bem conhecida é: "Nunca pintei sonhos, o que eu representava era minha própria realidade". No presente artigo, buscaremos os indícios de que a imaginação e a realidade não estão distanciadas, e que as imagens vistas na tela da artista não são ligadas exclusivamente ao campo onírico. As imagens, na visão fenomenológica, possuem uma estrutura intencional; elas são uma relação 
da consciência com o objeto. Dessa forma, veremos que as imagens de um corpo mutilado, "deficiente" ou incapaz de gerar um feto, em Frida Kahlo, atravessam caminhos de apreensão dos objetos a serem pintados ou escritos num diário ${ }^{1}$. Percepção, pensamento e imagem são tipos de consciência distintos, para Jean Paul Sartre (1964), que segue a linha da fenomenologia em $A$ imaginação e concebe a imagem como uma realidade psíquica certa - a imagem não poderia, em seu modo de ver, reduzir-se apenas a um conteúdo sensível.

Nessa concepção, Frida apreenderia seus temas sobre a maternidade e sobre a morte, por exemplo, tendo a consciência deles, ou seja, tendo percepção dessas imagens em sua obra. Mas é importante notar que a existência como coisa e a existência como imagem são pontos distintos, para Sartre. Ele exemplifica que uma folha em imagem e uma folha na realidade são uma única e mesma folha em dois planos diferentes de existência. 0 que as diferencia é a percepção; a apreensão do objeto. 0 imaginário seria a consciência imaginante que constitui o objeto. Sartre traz para o diálogo vários pensadores da imagem - de Descartes a Bergson. 0 primeiro, com sua dicotomia imagem x pensamento; o outro com ideias metafísicas, distantes da psicologia. Mas é com Edmund Husserl que ele segue concordando: uma consciência é sempre consciência de alguma coisa (SARTRE, 1964).

Pela lógica de imagens da consciência, qual o lugar do surrealismo nessa discussão?

Bergson (18962 apud SARTRE, 1964) afirma que o inconsciente é da mesma natureza do consciente: "Não há não-consciente para Bergson, há somente consciente que se ignora [...]" (SARTRE, 1964, p. 38). Voltemos então para o cenário surrealista que se instaurava na Europa e no México nos anos 1930. André Breton, considerado o "papa" do Surrealismo por seu Manifesto escrito em 1924, chega ao México na primavera de 1938. Ele, junto com René Magritte e Salvador Dalí, já exploravam as novas teorias de Sigmund Freud sobre o inconsciente; sua viagem ao México teve o propósito de visitar Trotsky e conhecer o local surrealista por excelência. Não se decepcionou. Breton achou a obra de Frida Kahlo uma manifestação espontânea de surrealismo puro. Mas é importante a reflexão sobre esse movimento: ele não deve ser concebido apenas como uma falta de lógica ou manifestações do inconsciente; deve ser pensado por outra dimensão, que é a de mostrar outra realidade, como sugere o escritor Carlos Fuentes:

\footnotetext{
${ }^{1}$ Nosso entendimento é que o diário também é composto por imagens - passa pelo código escrito, mas o processo de escrita traz imagens que serão corporificadas ali.

2 BERGSON, Henri. Matière et mémoire. 1896. Apud Sartre (1964).
} 
Ela descobriu uma coisa que nós latino-americanos sabemos muito bem, que nós já convivíamos com o surrealismo muito antes da França codificálo na década de 20, após a Primeira Guerra Mundial. Os grandes artistas surrealistas vieram da Alemanha (Max Ernst), da Espanha (Luis Buñuel) ou do México (Frida Kahlo) porque estavam ligados a uma cultura que sempre soube que existe um outro mundo além do mundo que conhecemos. Lado a lado com a realidade, percebemos que há outra realidade invisível. É que o dever do artista é tornar esta invisibilidade visível. (THE LIFE..., 37"3).

Quando se trata de experiências sugeridas ou construídas pela razão, a ordem é uma verdade e a desordem é um erro, ironiza Gaston Bachelard (1996, p. 5). Ele atesta que a revelação de um conhecimento científico não tem a ver somente com racionalização ou somente com o sensível, mas ambos se mesclam:

Quando o conhecimento empírico se racionaliza, nunca se pode garantir que valores sensíveis primitivos não interfiram nos argumentos. De modo visível, pode-se reconhecer que a ideia científica muito usual fica carregada de um concreto psicológico pesado demais, que ela reúne inúmeras analogias, imagens, metáforas, e perde aos poucos seu vetor de abstração, sua afiada ponta abstrata (BACHELARD, 1996, p. 19).

Bachelard, adepto de muitas contribuições da Psicanálise freudiana, acaba, no entanto, divergindo em outros pontos da teoria psicanalítica no que toca às representações do imaginário. Se para Freud há sempre algo oculto no inconsciente que nem sempre pode ser revelado senão por hipnose, sonho ou análise, para Bachelard as imagens poéticas são manifestações do imaginário e podem ser representadas através da linguagem numa condição consciente. Na perspectiva freudiana, a linguagem pode ocultar um desejo, mas para Bachelard não há máscaras, nada é encoberto - a linguagem poética não mostra para além dela mesma; a linguagem é a realidade em si.

A linguagem pictórica explícita compõe a obra de Frida Kahlo. Sua vida de dor e de sofrimento vai sendo o substrato de sua pintura e de seus relatos. Desde pequena a ligação mãe-filha lhe deixa ressentimentos: houve um distanciamento forçado logo nos seus primeiros meses e então Frida teve a substituição do peito da mãe por uma ama de leite, pois a mãe agora amamentaria sua irmã Cristina, que nasceria pouco depois dela. E sempre antes da mamada, a ama lavava seus peitos. Frida descreve com ressentimentos esse fato, e resulta dessa memória uma pintura na qual atribui a si um rosto adulto e um corpo infantil.

337 " se refere à minutagem do filme em que a fala transcrita é feita. 
Figura 1 - Mi nana y yo, de 1937

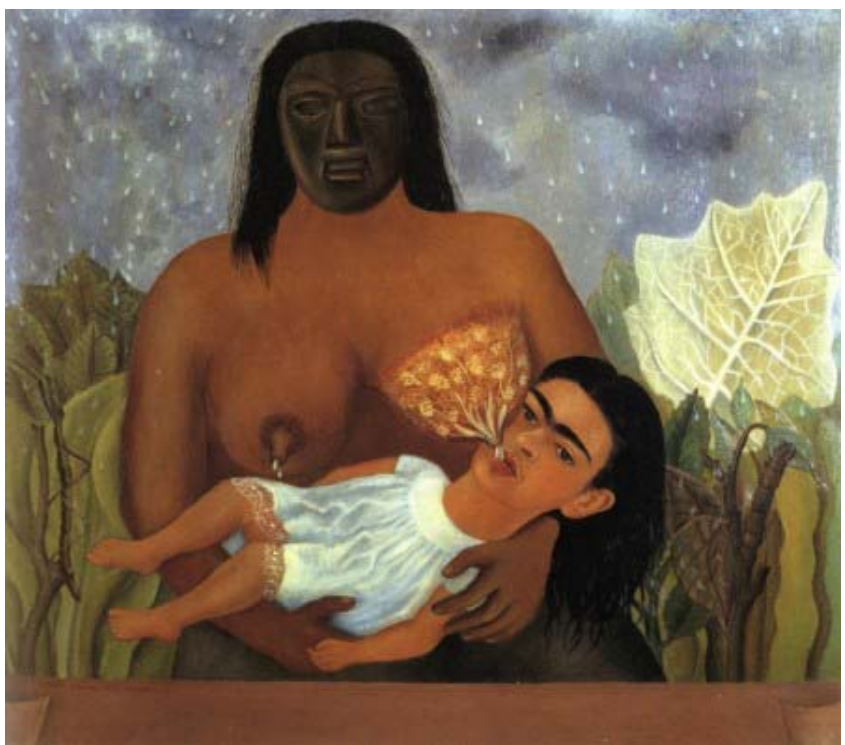

Fonte: Frida... (2005).

Essa imagem a traz nos braços de uma ama de leite de rosto obscuro, sugando um leite que se mostra através dos ductos e que se multiplica pelo derramamento do outro seio da ama e pelo céu - uma chuva de leite num dia tempestuoso. 0 escurecimento desse rosto (uma máscara funerária pré-colombiana) parece demonstrar uma negação de afeto a essa mulher que lhe amamenta. A respeito da separação abrupta entre mãe e filho, Gilbert Durand (1997, p. 73) observa que antes do desmame outra separação repentina já havia acontecido para o bebê - o parto. Ele afirma: "As primeiras experiências dolorosas da infância são experiências de mudança: o nascimento, as bruscas manipulações da parteira e depois da mãe e mais tarde o desmame" (DURAND, 1997, p. 74).

Frida tem certa obsessão pela maternidade e esse sentimento é representado ao longo de sua obra. Diego Rivera é também tratado por ela como "meu bebê" e tal afeição maternal pode ser transposta para além de uma relação conjugal. A pintura El abrazo del amor entre el universo, la tierra (México), yo, Diego y el señor Xólotl, de 1949, elucida muito bem essa relação de cuidado e colo que Frida dá a Diego como se ele fosse seu filho. Chamanos a atenção a terra que a abraça em sinal de acolhimento na figura de mãe-natureza ${ }^{4}$, que, por sua vez, é abraçada pelo universo. E mais uma vez uma gota de leite escorre de um peito inserido na figura da "Mãe Terra". 0 "terceiro olho" na testa de Diego representa a sabedoria

\footnotetext{
4 “Com o propósito imbuído de ideologia, desenhava a artista os fundos de seus autorretratos, escolhendo atributos que acompanhassem sua imagem. Levou a flora e a fauna mexicanas a suas exposições, desenhou cactos, plantas da selva, rochas de lava, macacos, cachorros Itzcuintli, cervos, papagaios - animais que ela tinha como animais de estimação e que aparecem em seus quadros como companheiros de solidão." (KETTENMANN, 1999, p. 27, tradução nossa).
} 
vinda desse homem que ela tanto admira. No entanto, um elemento, um tanto escondido, mas presente, também configura esta imagem: o sangue que parece escorrer de seu seio, cobrindo toda sua perna e pescoço. Junto do seio escorre também leite materno.

Figura 2 - El abrazo de amor entre el universo, la tierra (México), yo, Diego y el señor Xólotl, de 1949

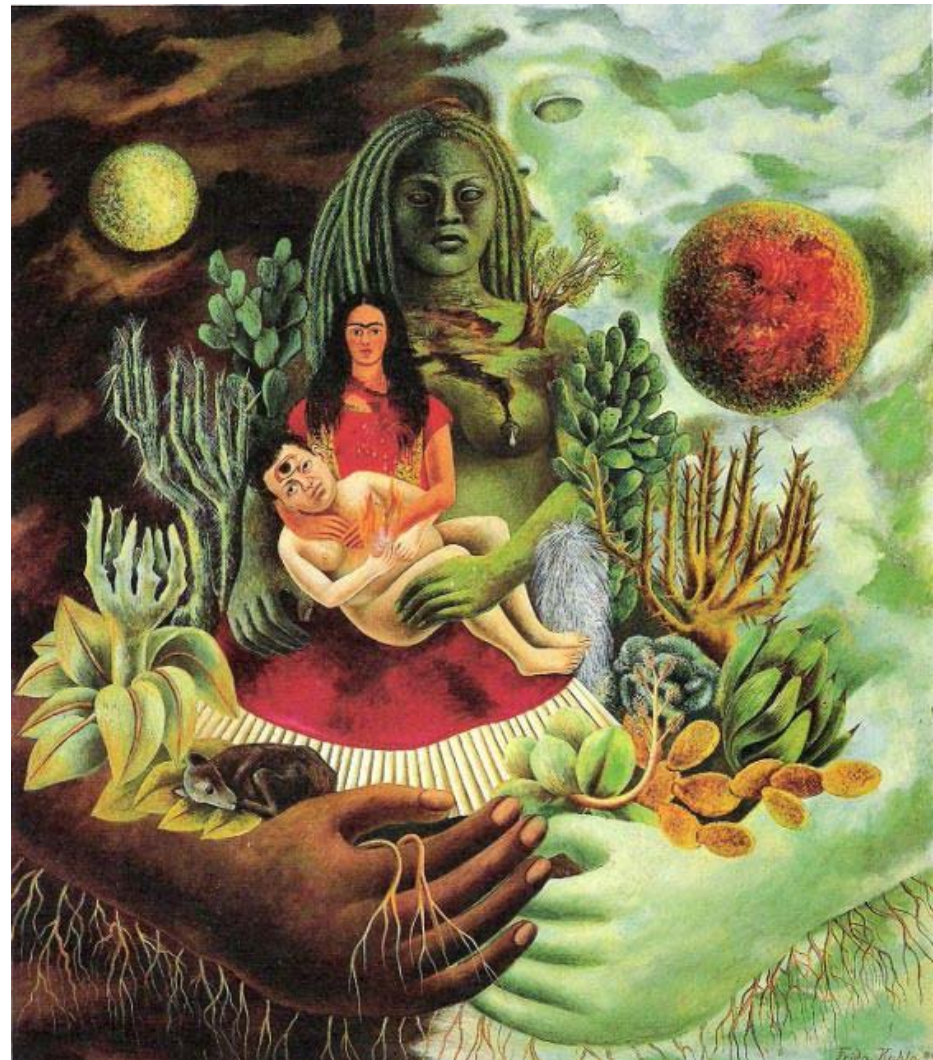

Fonte: Frida... (2015).

Luis Roberto Vera (2013, p. 303) afirma que nesse quadro é possível perceber os quatro elementos que Frida Kahlo costuma reunir em sua obra: identidade, pertencimento, maternidade e afeto. E é com Peter Sloterdijk (2016) que encontramos elementos que podem elucidar ainda mais essa obra: o filósofo alemão busca nos povos neolíticos aproximações entre a maternidade e a terra (lugar de pertencimento); a mulher e o conhecimento: o seio materno é a busca pelo conhecimento, converte-se no lugar da verdade.

Nesse paradigma o que importava era saber a qual família o indivíduo pertencia, qual sua linhagem e de qual seio ele foi amamentado. 0 seio materno, assim como a vulva, 
simboliza um portal que leva o homem à compreensão dos antepassados, ao autoconhecimento:

[...] o regaço feminino, com seu portal e seu corredor, submete-se a uma mudança imprevisível de significação: de agora em diante, ele não é mais apenas ponto de partida de todos os caminhos para o mundo, torna-se também o término das grandes viagens de retorno, que devem ser empreendidas no interesse da agora urgente pesquisa dos ancestrais, da interrogação dos mortos e do renascimento - em suma, da autoidentificação (SLOTERDIJK, 2016, p. 250).

Prosseguindo na busca pela verdade, nas filosofias etiológicas dos gregos, é às mães "que se descerá para descobrir, junto delas e nelas, alguma coisa que, sem enrubescer, se denominará conhecimento" (SLOTERDIJK, 2016, p. 250). O filósofo enfatiza ainda que o mais importante do autoconhecimento é esse interior poderoso do feminino do qual as árvores da sabedoria possuem profundas raízes. Ele lembra que nas "cavernas" femininas estão o princípio e o fim (o nascimento e a morte), e, portanto, a maternidade e a gravidez são formas do pensamento em sua totalidade. Aos nascidos importa

[...] ao menos uma vez na vida empreender a viagem à origem, pois é somente assim que se pode compreender a vida que dela brotou. Tão logo o órgão feminino do nascimento deixa de significar apenas a saída - real ou imaginária -, mas se torna também uma entrada pela qual deve passar a busca da identidade, ele se carrega de fascinações ambivalentes. A sangrenta porta para a vida, cuja abertura fascina, indigna e repele, tornase agora um acesso ao que subjaz e transcende o mundo (SLOTERDIJK, 2016, p. 251).

Essa transcendência seria uma morte simbólica como nas iniciações ritualizadas ou como o exitus real. Em ambas as mortes - a simbólica ou a real -, o morto volta à mãe (o útero). Na era "metafísica", como propõe Sloterdijk, o seio materno é um símbolo de regresso do ser humano à busca da verdade. A equivalência entre mamas e sepultura representa transformações sequenciais - a saída de um prepara a entrada do outro. As gestações estão ligadas às imagens do interior, a essa volta às origens e ao que nos remete a esse retorno. Sloterdijk (2016, p. 253) designa esse processo como a "fetalização geral das imagens do mundo". Além disso, a equivalência entre túmulo e útero lhe parece bem pertinente na premissa topográfica das metafísicas primitivas. As imagens do feminino estão associadas a motivos míticos, tais como: terra e casa; campo e pedra funerária; nascimento e semente, colheita e mundo de dentro; mar e barco; e inferno e ovo.

Ainda na obra El abrazo del amor entre el universo, la tierra (México), yo, Diego y el señor Xólotl há um acolhimento, uma junção entre cinco seres: ela, Diego, o universo (céu - 
noite e dia), a terra (México - natureza) e o senhor Xólotl 5 . Essa obra evidencia a união de tudo, as dicotomias todas num diálogo, misturando-se numa mesma imagem. Luis Roberto Vera comenta as tais dualidades enfatizando que são simbologias contrárias, mas que não se separam, são complementares:

No caso da composição de $O$ abraço entre o universo, a terra (México), eu, Diego e o senhor Xólotl chamam a atenção a convergência das formas piramidais e de círculos concêntricos como cosmogonia mesoamericana que reúne o sol e a lua, o dia e a noite, a terra e a água, ao masculino e o feminino como os movimentos de arsis e thesis de um ritmo vital (VERA, 2013, p. 310, tradução nossa6).

A relação entre lua e feminilidade também pode ser lida pela perspectiva mítica. Durand (1997, p. 103) lembra que o isomorfismo da lua e das águas é uma feminização e o intermediário entre a lua e a mulher é o ciclo menstrual. 0 pensador assinala diversos casos em que há evidências dessa relação: a crença, em algumas civilizações, de que a lua é o primeiro marido das mulheres; o fato de as jovens virgens não olharem para a lua para não ficarem grávidas (cultura dos esquimós) ou de ficarem "aluadas" (cultura bretã), entre outras crenças.

Estendendo essa discussão para a abordagem do feminino em Frida, poderemos pensar em suas gestações. Um ano após seu casamento com Diego, em 1929, ela engravida e os médicos recomendam um aborto por razões de suas debilitações sofridas com as várias cirurgias decorrentes do acidente passado. Depois, quando morava em Detroit no ano de 1932, Frida engravida novamente contra o prognóstico médico que apontava a impossibilidade de uma gravidez e muito menos um parto por via vaginal, já que sua pélvis apresentava três roturas. Consulta-se então com um profissional de sua confiança no Hospital Henry Ford, em Detroit, e ouve dele que seria melhor preservar a criança do que submeter-se a um aborto, mantendo a gravidez e fazendo uma cesárea no tempo oportuno (KETTENMANN, 1999, p. 32). Decide então levar adiante a gravidez, mas ocorre um aborto natural. Ela passa então para as telas esse sentimento de impotência perante a maternidade, como na imagem a seguir intitulada Henry Ford Hospital o La cama volando.

\footnotetext{
50 Xólotl "[...] foi uma raça de cachorros sem pelo, originária do México. Conta com três mil anos de antiguidade; foi um presente que o deus Xólotl deu aos homens para a salvação de sua alma. Na tradição oral mexicana, Xólotl representava o Senhor da Estrela da Tarde, do Inframundo; Deus do Relâmpago, Deus do Jogo de Bola e guia dos mortos em sua viagem ao Mictlan. Xólotl era irmão gêmeo de Quetzalcóatl e de Tlahuizcalpantecuhtli, Senhor da Estrela do Amanhecer, apesar de ser considerado o Deus do Azar, pois Xólotl personificava o lado maligno de Vênus e era associado com a doença e com as deformidades físicas." (IGLESIAS, 2013, doc. não paginado, tradução nossa).

${ }^{6}$ No original: "En el caso de la composición de El abrazo de amor entre el universo, la tierra (México), yo, Diego y el señor Xólotl llaman la atención la convergencia de las formas piramidales y de círculos concéntricos como una manera de articular la visión dual, opuesta y complementaria de la cosmogonía mesoamericana que reúne al sol y la luna, al día y la noche, a la tierra y al agua, a lo masculino y lo femenino como los movimientos de arsis y tesis de un ritmo vital." (VERA, 2013, p. 310).
} 
Figura 3 - Henry Ford Hospital o La cama volando, 1932

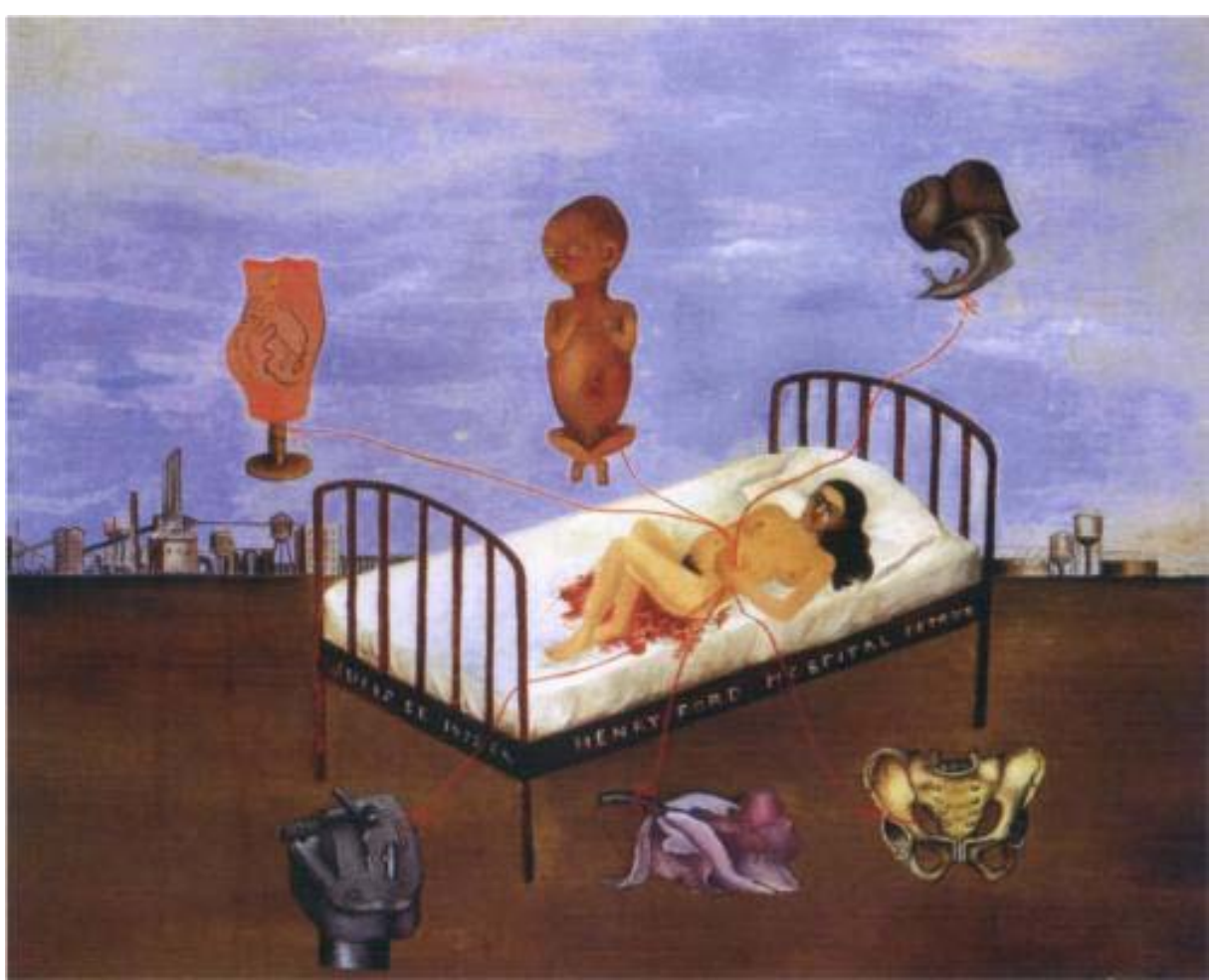

Fonte: Frida... (2005).

Na Figura 3, os elementos extrojetados de seu corpo remetem ao aborto e à impossibilidade de ser mãe: um órgão reprodutor feminino, um grande ${ }^{7}$ feto, a parte inferior de uma coluna vertebral, uma flor murcha, uma concha e um aparelho hospitalar, que, segundo Kettenmann:

O objeto é, possivelmente, parte de um esterilizador de vapor, como os que se utilizavam então nos hospitais. Trata-se de uma peça mecânica que era usada como válvula de fechamento para depósitos de gás ou de ar comprimido, servindo como regulador de pressão. Frida Kahlo deve ter encontrado paralelismos, durante o período que ficou hospitalizada, entre este mecanismo de fechamento e sua própria musculatura "defeituosa", que a impedia de manter o bebê em seu corpo (KETTENMANN, 1999, p. 34, tradução nossa ${ }^{8}$.

A disposição espacial de Frida (escolhendo o canto direito da cama) parece simbolizar sua grande solidão, isolada da cidade industrial (ao fundo) e sobre a cama que

\footnotetext{
${ }^{7}$ Essa desproporção do bebê só nos leva a inferir a grande importância que ele tinha para Frida.

${ }^{8}$ No original: "El objeto es, posiblemente, parte de un esterilizador de vapor, como los que se utilizaban entonces en los hospitales. Se trata de una pieza mecánica que se utilizaba como tapa de cierre para depósitos de gas o de aire comprimido, sirviendo como regulador de presión. Frida Kahlo ha debido encontrar paralelismos, durante su estancia en el hospital, entre este mecanismo de cierre y su propia musculatura «defectuosa», que le impedía conservar al niño en su cuerpo." (KETTENMANN, 1999, p. 34).
} 
parece flutuar. 0 sangue tingindo o lençol marca o sofrimento. 0 nome do hospital e o ano do ocorrido são assinalados também. 0 fio que liga os elementos sobre e sob a cama saem de Frida como uma metáfora de suas veias que parecem ligar todos esses elementos representativos do aborto.

A flor murcha, de cor roxa, Diego havia lhe dado por saber que ela gostava de recebêlas. O significado da flor, de acordo com Kettenmann (1999, p. 34), é o do sentimento e da sexualidade entre Frida e Diego. Mas um dos elementos do quadro chama a atenção por sua grande carga simbólica: a concha. Há declarações de Frida sobre a relação da concha com a lentidão e com o aborto, segundo Kettenmann (1999, p. 33). O caracol aparece em representações para designar vida e sexo, além do fato de nas culturas indianas ele ser considerado símbolo de concepção, gravidez e parto - devido à sua forma redonda. Relaciona-se, ainda, com a lua crescente e minguante, quando o molusco que habita a concha entra e sai de sua proteção. Por último, remete ao ciclo e à sexualidade feminina. Bachelard também dedicou um capítulo de $A$ poética do espaço à concha. Ele nos lembra de Paul Valéry e sua poética sobre o caracol, trazendo a seguinte reflexão: “[...] é preciso viver para construir sua casa, e não construir sua casa para viver nela" (BACHELARD, 1993, p. 118). A barriga de uma gestante que cresce (a casa) é em função do bebê (molusco) e não o contrário. A conotação da concha com o pensamento maternal se sustenta pela proteção, pelo crescimento, pela formação. Bachelard afirma, inclusive, que é a formação, e não a forma, que permanece misteriosa no caracol. 0 mistério da vida teria seu encantamento justamente na lenta e contínua formação. Mas a formação fetal pode ser interrompida. A concha pode ser vazia. O ninho, vazio. A imagem do ninho, tal como a da concha, em Bachelard, é carregada de poeticidade:

A vida desgasta rapidamente os primeiros espantos. Aliás, para uma concha habitada, quantas conchas vazias! Mas a concha vazia, como o ninho vazio, sugere devaneios de refúgio. É sem dúvida um requinte de devaneio seguir imagens tão simples. Mas o fenomenólogo tem necessidade, acreditamos nós, de ir ao máximo da simplicidade. Por isso, consideramos interessante propor uma fenomenologia da concha habitada (BACHELARD, 1993, p. 119).

Pelo método fenomenológico, enfatizamos também a imagem como um excesso da imaginação e, por isso, podemos considerar a concha da tela de Frida como dialéticas de oposições: o oculto e o manifesto; o cheio e o vazio; o plácido e o ofensivo; o interior e o exterior. A força do oculto pode estar na preparação da saída, na libertação das 
correntes/concha, conforme Bachelard: "O que não se pode esperar de um ser liberto das correntes!" (BACHELARD, 1999, p. 122).

Figura 4 - Mi nacimiento, de 1932

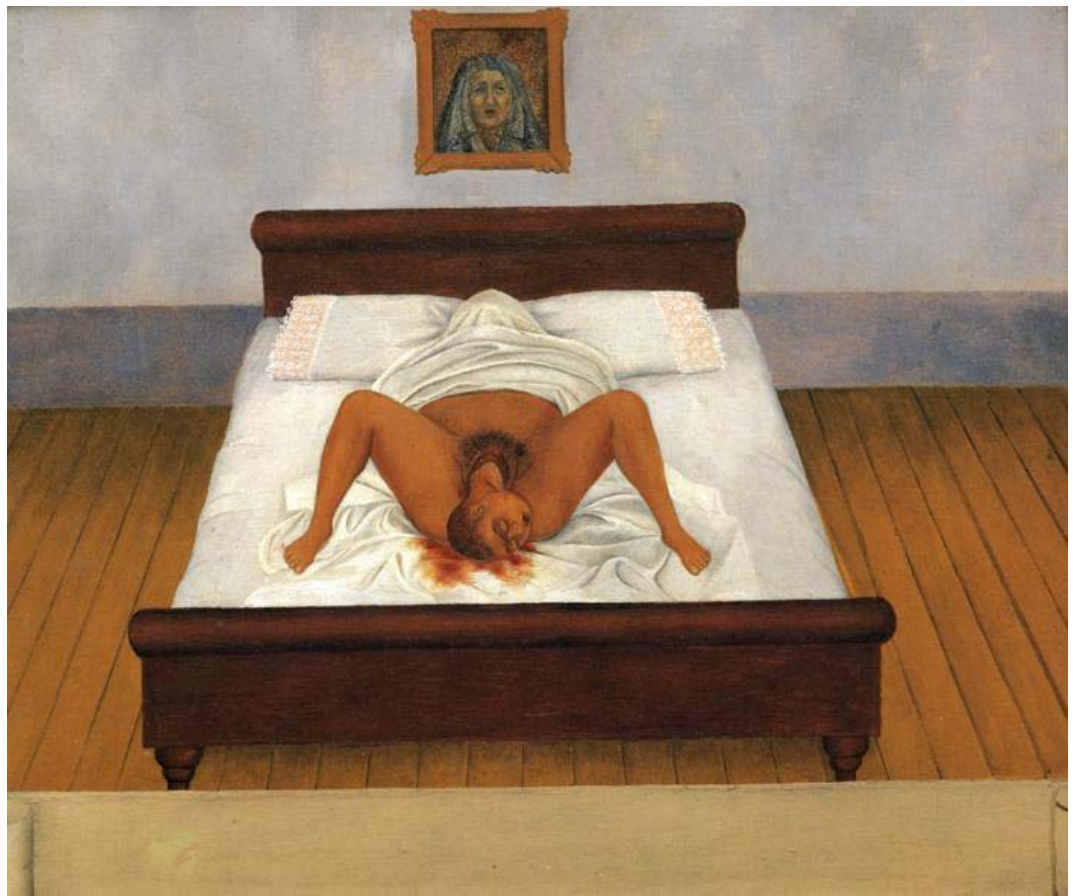

Fonte: Frida... (2005).

Na pintura Mi nacimiento (1932) (Figura 4), vemos Frida sendo parida enquanto um lençol cobre o rosto de sua mãe. Durante a feitura dessa obra, a mãe de Frida faleceu e o lençol remete a um cadáver coberto. A dicotomia morte-vida fica evidente: enquanto um novo ser chega ao mundo, o outro, parte. 0 sangue, nas obras de Frida, está sempre ligado ao sofrimento: ao aborto, às cirurgias, aos ferimentos, a Diego (amor-dor). Mas até mesmo o sangue menstrual e o parto podem ser pensados através de uma violência interna. 0 sangue menstrual seria justamente um indício de que não há gestação em curso, a falta de um feto no útero provoca sangramento: se há menstruação, não há gravidez. E o sangue menstrual não aparece nas obras da artista mexicana; pelo contrário, nelas aparece o sangue de abortos. Em Frida conseguimos visualizar tanto a morte dos fetos, mas também a sua própria morte em várias obras. Em Mi nacimiento (1932), embora a representação da morte esteja ligada a sua mãe, que está coberta com um lençol branco, vemos também sua própria cabeça, nascendo através do parto normal, de olhos fechados. Na parede, uma senhora com fisionomia semelhante à de sua mãe testemunha o nascimento. Duas cabeças que 
estabelecem a relação vida-morte. A cabeça está nessa passagem (a vulva) que Sloterdijk (2016) denomina "porta mágica". 0 pensador alemão afirma que, na época do pensamento originário, todas as reflexões em princípio dirigiam-se para a vulva, que dava acesso à penumbra uterina. A vulva, segundo ele, é uma porta materna que serve como entrada e como saída - não no sentido erótico, mas religioso, que abarca toda a existência.

0 tema da morte é recorrente no imaginário de Frida. Ela tinha sobre o dossel de sua cama um esqueleto com o intuito de sempre lembrar sua mortalidade - fato que dava margens para Diego brincar que esse esqueleto era o amante da companheira. As inúmeras camas pintadas por Frida coincidem com o que Durand (1997) chama de eufemização da morte: o túmulo "torna-se" berço. E na pintura El sueño o La cama (1938) esse esqueleto aparece velando seu sono.

Instalamos as camas nos quartos, em "cantos", em lugares aconchegantes de uma casa para que ali possamos repousar. A Figura 5 evidencia uma transposição do sono para o lugar do aéreo, do eólico, da leveza. Uma cama voando, como um dos títulos atribuídos à imagem sugere; ou parada entre as nuvens de um céu tenebroso.

Figura 5 - El sueño o La cama, de 1938

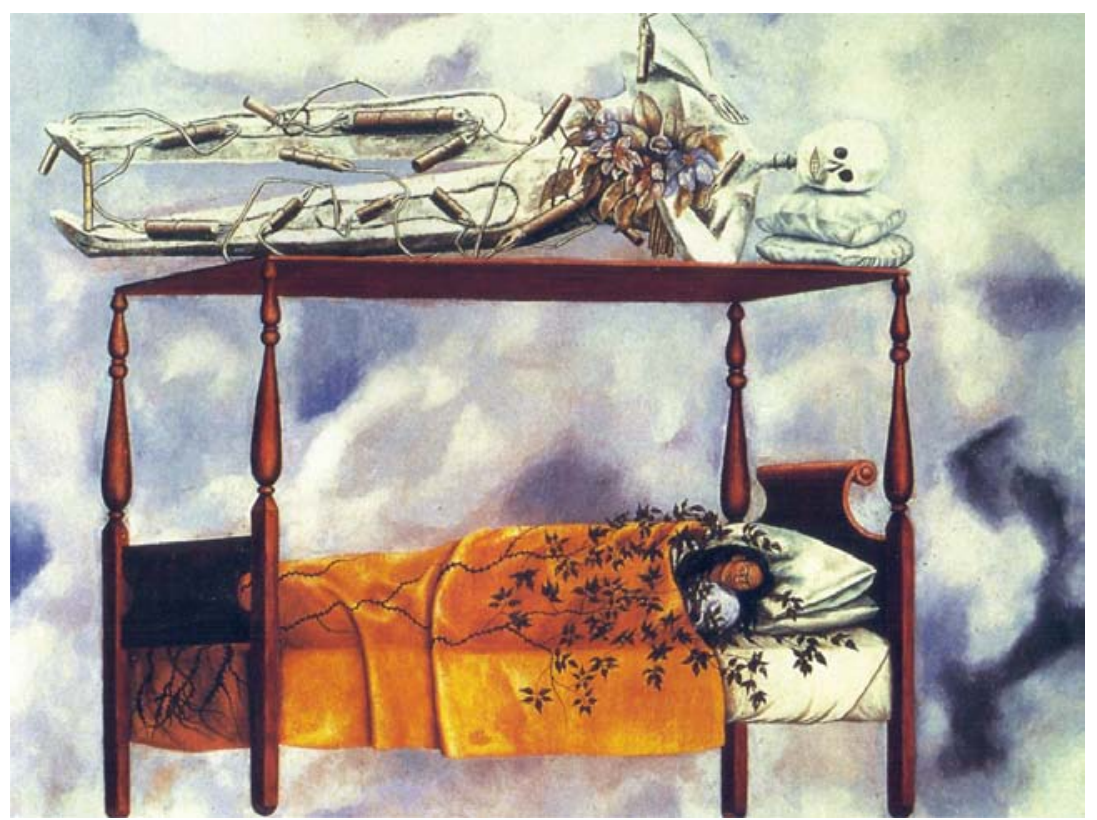

Fonte: Frida... (2005).

Os cantos de uma casa, segundo Bachelard, são o espaço do interior, da intimidade. Nas suas palavras, "todo canto de uma casa, todo ângulo de um quarto, todo espaço reduzido 
onde gostamos de encolher-nos, de nos recolher a nós mesmos, é, para a imaginação, uma solidão (BACHELARD, 1993, p. 145). Frida subverte esse lugar da sua solidão para uma espacialidade sem barreiras; não há paredes; não há bloqueios para seus sonhos. Seu espaço de repouso contrasta com a leveza que é própria do céu com os tons que ele carrega, nuvens alvas se mesclando ao chumbo. Acima dela, o esqueleto: a visão para a morte. Em contraposição à imobilidade de um quarto, a cama voa. Talvez seus pensamentos descansem nesse lugar sem limites, seus sonhos ou pesadelos estão livres. Mas a noção bachelardiana de canto sugere o quarto como um refúgio, um lugar onde a consciência fica em paz, imóvel. Somos o espaço onde estamos:

Um quarto imaginário se constrói ao redor do nosso corpo, que acreditamos estar bem escondido quando nos refugiamos num canto. As sombras logo se tornam paredes, um móvel é uma barreira, uma tapeçaria é um teto. Mas todas essas imagens imaginam demais. É preciso designar o espaço da imobilidade fazendo dele o espeço do ser (BACHELARD, 1993, p. 146).

E Frida, sem os cantos que delimitam seu espaço interior, se esquivaria de tal imobilidade? Estaria ela enraizada nessa cama ou sob flores que a libertam?

Ítalo Calvino (1990), em Seis propostas para o próximo milênio, sugere, dentre outros elementos, que a leveza seja pensada como um fator primordial na composição literária deste milênio, e, não obstante, na composição das artes em geral. Calvino lembra a obra $A$ insustentável leveza do ser, em que Milan Kundera não coloca a leveza como oposição ao peso: os dois se complementam. E mesmo quando optamos pela leveza, o peso vem junto:

[...] na vida, tudo aquilo que escolhemos e apreciamos pela leveza acaba bem cedo se revelando de um peso insustentável. Apenas, talvez, a vivacidade e a mobilidade da inteligência escapam à condenação - as qualidades de que se compõem o romance e que pertencem a um universo que não é mais aquele do viver (CALVINO, 1990, p. 19).

Sua proposta, nesse sentido, então, é "voar para outro espaço" a cada vez que o peso estiver nos condenando. É o que faz Frida, se não na vida, na pintura. Aqui, seu aforisma "Pés para que os quero se tenho asas para voar", escrito sob seu desenho de pés amputados, em 1953, em seu diário, faz todo sentido. Unir o esqueleto (a morte) com o elevado; o sono com o aéreo, as plantas que não se enraízam ao solo é tentar dar leveza para o que é pesado. Podemos pensar que a partir da angústia e consciência da morte, o indivíduo opta por maneiras de suavizar o sofrimento de modo que toma atitudes imaginativas para negar e ultrapassar a morte ou inverter seus significados para algo mais ameno, menos doloroso. 0 imaginário seria um meio de acessar esse eufemismo diante dos sofrimentos da vida e da 
angústia pela morte em devir. Frida Kahlo não pintava por hobby, mas por uma necessidade de expressão e de minimizar sua dor, pintava "sua própria realidade", como ela mesma afirmava. Da mesma maneira que a pintura estabelecia uma ponte entre o martírio de seu corpo ferido e a redenção, o prazer e o alívio, o diário também lhe dava acesso a uma consciência de si, um conhecimento em direção a ela mesma. Frida Kahlo rascunhava, rasurava, manchava papéis que extrapolavam o limite da página indo manchar a folha seguinte. Suas letras, grandes e apressadas (ver imagem a seguir), assim como suas pinturas, são simbólicas e representam um estado de espírito, tal como o sangue avança sem que se consiga contê-lo. As manchas nas páginas eram um modo de escamotear a morte, como podemos perceber nesse desabafo: "Quem diria que as manchas vivem e ajudam a viver? Tinta, sangue, cheiro. Não sei que tinta usar, qual delas gostaria de deixar desse modo o seu vestígio." (KAHLO, 2015, p. 5).

Figura 6 - Letra de Frida Kahlo

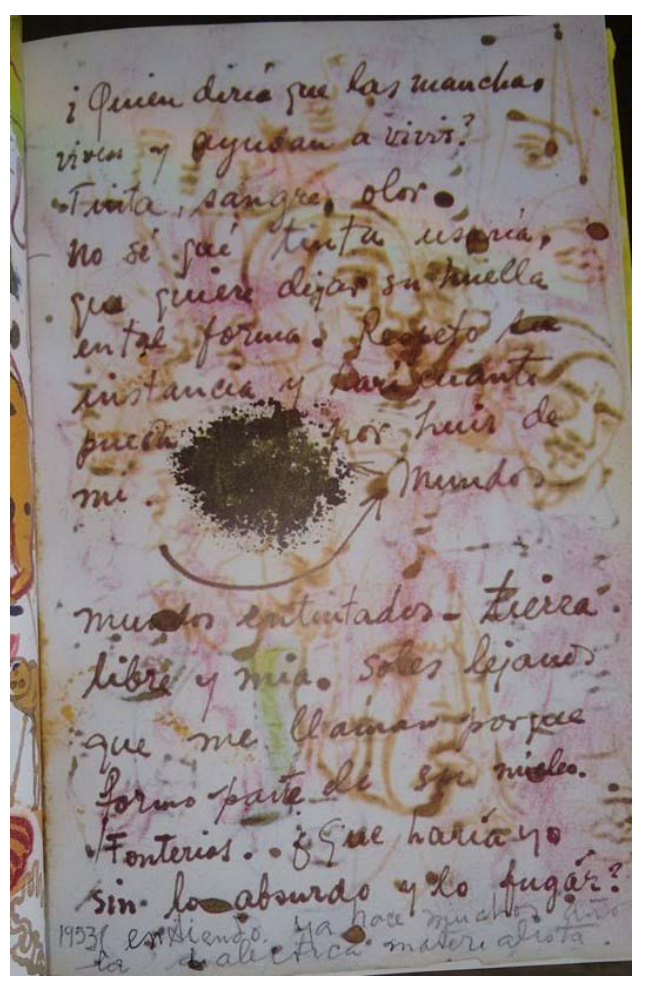

Fonte: 0 diário de Frida Kahlo (KAHLO, 2015).

O sangue, o cheiro e a natureza são partes desse imaginário que se atrela à maternidade, em Frida. Em seu diário, tanto quanto nas pinturas, a simbologia vem também em palavras aparentemente desconexas, que misturam, por exemplo, estado de espírito, 
animais, natureza, partes do corpo, cores, manifestações de fé, entre outros. Aqui, muito fortemente, conseguimos perceber elementos semelhantes ao Surrealismo, e, por vezes, parece-nos que estamos lendo uma escrita automática (poema dadaísta), como é o caso desses escritos de 1916:

Não lua, sol, diamante, mãos - $/{ }^{9}$ ponta do dedo, ponto, raio, gaze, mar. / pinheiro verde, vidro rosa, olho, / grafite, borracha, lodo, mãe, vou. / = amor amarelo, dedos, menino útil, flor, desejo, ardil, resina. / potreiro, bismuto, santo, sopeira. / galho, ano, estanho, outro potro. / pontilhado, máquina, arroio, sou. / metileno, monotonia, câncer, riso. / gorjeio - olhar - pescoço, vinha / cabelo negro seda menina vento $=/$ pai pena pirata saliva / tirar mordaça consumo vivaz / onda - raio - terra - vermelho sou. / Abril, dia 30. / menino - coalho, seu, rei, rádio negro - / álamo então procuro - mãos. Hoje. / Olmo. Olmedo. Violeta. Canário / zumbido. Pedrada - brancura do cinza / caminho - silhueta - ternura / seguidilha gangrena - Petrarca - / girassol - azuis sinistros. Agudo / Romeiros circunlóquios - esterco - ontem / regaço - desmoronando - arrimo - / visões - irreal - adormecida - pilar (KAHLO, 2015, p. 191).

Esboçar um imaginário da maternidade, em Frida, é algo atemporal. Os termos usados no diário podem remeter a imagens ancestrais que comunicam sentimentos evidentes ou mais adormecidos, mas se mostram, se fazem presentes, e estão no campo do sagrado. E suas gestações são os espaços esféricos de agrupamento, tal como Sloterdijk descreve o estar-com-outro (tanto no sentido social como cósmico).

O México, por muito tempo, manteve tradições indígenas de medicina natural e o parto estava no rol de cuidados da mulher. Ao ser privada de carinhos após o nascimento de sua irmã Cristina, Frida cresceu desejando cuidar: de Diego, dos animais, de um filho. Os aportes de medicina do México do período colonial apontam que houve uma tradição de cuidados com a gestante devido à importância que se dava aos futuros filhos, ou seja, fazer nascer bem um filho significava que futuramente este ajudaria a família no trabalho agrícola. Assim, as parteiras tinham uma posição privilegiada na sociedade (BROWN, 1990, p. 6).

Consideramos a lógica presente nas imagens de Frida Kahlo, artista que dizia pintar sua própria realidade, como um dinamismo organizador que revelava a consciência da sua dor - fossem pensamentos simples, empobrecidos ou até os mais elaborados. As imagens (não as reduziremos ao universo da artista mexicana ${ }^{10}$ ) vão para além do inconsciente. A apreensão das imagens e os pensamentos em relação à sua natureza dão aos indivíduos a consciência da imagem. Frida tinha a percepção do que, como e por que optava por aquelas

\footnotetext{
${ }^{9}$ As barras (sinais gráficos), aqui, sinalizam a mudança de linha no diário de Frida.

${ }^{10}$ Não pretendemos reduzir esse conceito de imaginário às telas de Frida Kahlo, uma vez que as teorias dão sustentação para que possamos pensar a imagem, e não o contrário.
} 
figuras maternais, pelo sangue, pelos fetos ou bebês. Até mesmo a representação simbólica, como as conchas, por exemplo, era uma opção consciente. A imaginação dribla a percepção, e, assim, a comunicação pode ser enviesada por esses símbolos dos quais o imaginário se alimentou. Ou, como diria Jean-Paul Sartre: "A consciência é ato e tudo o que existe na consciência existe em ato" (SARTRE, 1964, p. 31). São essas "atitudes imaginativas" que resultam de sua produção artística, com seus símbolos, imagens ou arquétipos. Poderíamos afirmar, então, que sua consciência perante a morte, seus "fantasmas" acerca da maternidade levavam à formação de um imaginário o qual conseguimos identificar em sua obra, tendo, como função principal, o equilíbrio biopsicossocial diante da finitude humana.

Escrever ou pintar é uma forma de não morrer, de postergar o fim, de amenizar a dor. 0 imaginário da maternidade está presente nas obras porque, para Frida, o corpo como gerador de um novo ser tornou-se uma obsessão. Tereza Arcq, curadora da exposição Frida Kahlo: conexões entre mulheres surrealistas no México, aponta que Frida:

[...] reelabora os códigos estéticos do imaginário médico e os impregna de carga emotiva. Num claro contraste com o desenho a lápis de seu corpo nu e idealizado por Diego Rivera em Frida y el aborto, ela mostra as suas entranhas, seu corpo dividido (FRIDA..., 2015).

Figura 7 - Frida y el aborto (1932)

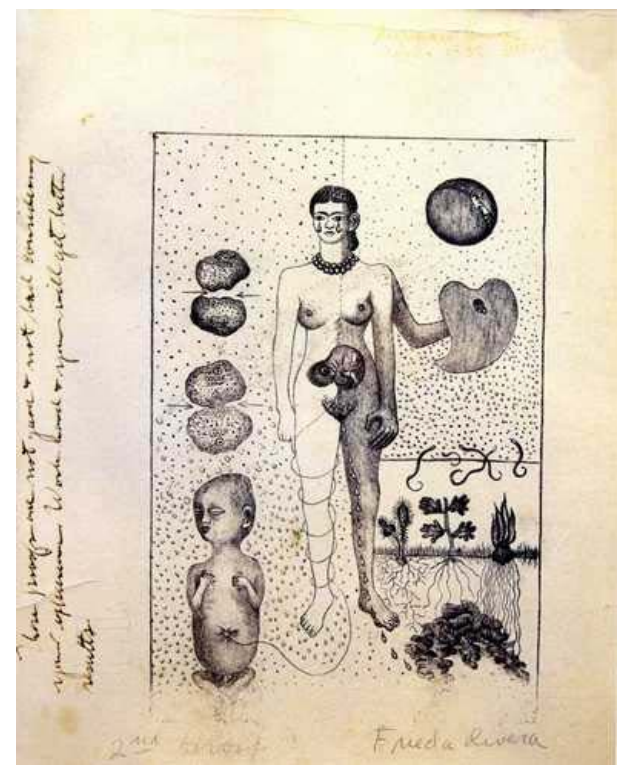

Fonte: Frida... (2015).

Vemos então um feto fora de seu corpo conectado pelo cordão umbilical à esquerda. Arcq completa: 
O lado direito e racional representa o processo científico da gestação, ao passo que o esquerdo, onde está o coração, sangra. As gotas confundem-se com suas lágrimas e caem na terra, fertilizando-a. Um terceiro braço sai do coração e segura uma paleta, como se quisesse manifestar que seu corpo, incapaz de conceber um filho, só poderia criar por meio da pintura. Margo Glantz escreveu que para Frida Kahlo, 'a maternidade falha porque o corpo está destroçado, perfurado, danificado para sempre e a maternidade é abortada (FRIDA..., 2015).

0 imaginário feminino remete, além disso, ao labirinto (DURAND, 1995), que é uma imagem que se refere diretamente à vagina. 0 órgão sexual feminino é uma passagem, é biológico e pode dar acesso ao social também, uma vez que por ali nasce o ser humano que estará inserido no mundo. 0 clampeamento do cordão umbilical sinaliza a entrada desse indivíduo na cultura. Peter Sloterdijk concebe a placenta como uma esfera na qual todos nós fomos inseridos - o ventre é uma parede, é o elástico dos limites. E para além disso, a ligação mãe-filho se eterniza mesmo após a ruptura do cordão. A relação afetiva vai se constituindo desde aí e o sofrimento de Frida pelos abortos é totalmente explicável por essa relação mútua que ultrapassa a movimentação de fluidos. Sloterdijk explica:

[...] deve-se conceber uma fase de coabitação fetal em que a criança em formação experimenta presenças sensoriais dos líquidos, dos corpos moles e dos limites da caverna: o sangue placentário, em primeiro lugar, depois o líquido amniótico, a placenta, o cordão umbilical, a bolsa das águas e uma vaga representação preliminar da experiência de limites espaciais pela resistência da parede abdominal e do envoltório elástico. Como precursor daquilo que se chamará posteriormente a "realidade", apresenta-se aqui um reino intermediário fluido, acomodado em uma dimensão espacial esférica escura e suavemente acolchoada sobre paredes mais sólidas (SLOTERDIJK, 2016, p. 269).

Trazer à tona imagens que podem vir do inconsciente, como Freud ou Hume defendem, tem sua importância (SARTRE, 1964). No entanto, compreendemos que a exteriorização dessas imagens, a reflexão e a opção por elas, assim como sua "conexão" com o surrealismo, passam adiante no quesito imagem-pensamento. Talvez estejamos mais próximos de pinturas que encontrem na imagem um sentido que as vinculem ao pensamento, tal como em Leibniz, por exemplo, que vê aí um sentido de desvanecimento da imagem enquanto tal, dando-lhe "inteligibilidade". A imagem, assim, se acha penetrada de intelectualidade. Poder criar por meio da pintura, da imaginação, dos escritos é também dar vida a um corpo, mesmo que destroçado. É colocar no corpo uma função simbólica, social, cultural e até mesmo política. Não queremos, então, procurar o que há "por trás" das imagens, desnudá-las, pois elas mesmas, nuas, já são, em si mesmas, protótipos de um 
imaginário. Queremos, ao contrário, evidenciar uma linguagem poética, no sentido bachelardiano, que reúne a dor e a maternidade nas telas de Frida Kahlo.

\section{Financiamento}

Este trabalho foi financiado pela Coordenação de Aperfeiçoamento Pessoal de Nível Superior (CAPES).

\section{Referências}

ANAZ; Sílvio et al. Noções do imaginário: perspectivas de Bachelard, Durand, Maffesoli e Corbin. Revista Nexi, São Paulo, n. 3, 2014. Disponível em:

<https://revistas.pucsp.br/index.php/nexi/article/view/16760>. Acesso em: 24 jun. 2016.

BACHELARD, Gaston. A poética do espaço. São Paulo: Martins Fontes, 1993.

BACHELARD, Gaston. A formação do espírito científico: contribuição para uma psicanálise do conhecimento. Rio de Janeiro: Contraponto, 1996.

BROWN, Hugo A. Aportes de Mexico a la medicina. Mexico: Editorial Amaquemecan, 1990.

CALVINO, Italo. Seis propostas para o próximo milênio. São Paulo: Companhia das Letras, 1990.

DURAND, Gilbert. A imaginação simbólica. São Paulo: Editora Cultrix, 1995.

DURAND, Gilbert. As estruturas antropológicas do imaginário: introdução à arquetipologia geral. São Paulo: Martins Fontes, 1997.

FREUD, Sigmund. A interpretação dos sonhos. Porto Alegre: L\&PM, 2012. v. 1.

FRIDA Kahlo: conexão entre mulheres surrealistas no México. São Paulo: Instituto Tomie Ohtake, 2015. Exposição 27 setembro 2015 a 10 janeiro 2016. Curadoria de Teresa Arcq.

FRIDA Kahlo Fans. 2005. Disponível em: <http://www.fridakahlofans.com/>. Acesso em: 29 mar. 2017.

IGLESIAS, Sonia. Xólotl, el divino perro bermejo. In: LEYENDAS Mexicanas y Mitos Mexicanos. 2013. Disponível em: <http://www.mitos-mexicanos.com/leyendascortas/xolotl-el-divino-perro-bermejo.html> Acesso em: 3 jul. 2016.

JAMIS, Rauda. Frida Kahlo. 3. ed. São Paulo: Martins Fontes, 2015. 
KAHLO, Frida. 0 diário de Frida Kahlo: um autorretrato íntimo. 4. ed. José Olympio: Rio de Janeiro, 2015.

KETTENMANN, Andrea. Kahlo. Köln: Taschen, 1999.

SARTRE, Jean Paul. A imaginação. São Paulo: Difusão Europeia do Livro, 1964.

SLOTERDIJK, Peter. A clausura materna - Para a fundamentação de uma ginecologia negativa. In: SLOTERDIJK, Peter. Esferas I: bolhas. São Paulo: Estação Liberdade, 2016.

TERNES, José. Bachelard e Freud: alargar o espírito, tonificar a alma. Reflexão, Campinas, v. 31, n. 89, p. 101-110, jan./jun. 2006. Disponível em: <http://periodicos.puc-

campinas.edu.br/seer/index.php/reflexao/article/view/3105> Acesso em: 21 jun. 2016.

THE LIFE and times of Frida Kahlo. Direção: Amy Stechler. PBS Home Video. Color, 2005. 90 $\min$.

VERA, Luis Roberto. Maternidad: raigambre y clasicismo en el abrazo de amor en Frida Kahlo. In: VERA, Luis Roberto. Tramas. México: Universidad Autónoma del México, 2013.

\title{
The imaginary of motherhood in Frida Kahlo
}

\begin{abstract}
The imaginary of pain and motherhood in Frida Kahlo raises a reflection on the balance between the images present in consciousness as opposed to the dream field. In this sense, how to think the surrealism that many critics insist on labeling Frida's art? Our method is based on the analysis of some of Frida's paintings and her dialogue with phenomenological thinking about images, questioning the surrealist movement as a mere manifestation of the unconscious in art. The notion of motherhood is in agreement with the thinking of social groupings and spheres, as postulated by the philosopher Peter Sloterdijk. Our aim is to find out how Kahlo's artistic objects reveal the existence of pain and the maternal sense as immediate data of consciousness.
\end{abstract}

\section{Keywords}

Imaginary of motherhood. Frida Kahlo. Abortion. Pain. Consciousness.

Recebido em 30/03/2017

Aceito em 28/06/2017 